\title{
A questão da ciência no Brasil
}

\author{
OSCAR SALA
}

$\mathrm{H}$ esitei inicialmente em aceitar o convite do IEA para discutir o tema proposto. Entretanto, uma vez aceito o convite, quando, temerariamente, iniciei o preparo da palestra que trata em termos gerais de alguns problemas da ciência na época atual, dei-me conta da imensa literatura existente sobre o que é comumente classificado como política científica, que logo após a guerra tratava principalmente da responsabilidade do cientista perante a bomba atômica. Depois, o tema central deslocou-se para o problema da energia nuclear.

Há cerca de 10-15 anos apareceu um novo conceito, o de planejamento da pesquisa.

Quanto um país deve despender em pesquisa? Qual a proporção entre pesquisa fundamental e aplicada? A pesquisa deve ser feita nas universidades, nos centros de pesquisa do Estado? Qual a interação ou integração universidade-indústria? Quais as prioridades - física, química, biologia, oceanografia, astronomia? Numa dada área, qual a proporção de gastos em física de altas energias, física nuclear, física dos sólidos, óptica, termodinâmica, óptica eletrônica, etc., etc.?

Quantos doutorados por ano? Qual a taxa ótima de crescimento para cada disciplina, etc.?

Estas sáo algumas das questôes, entre outras, para todos os que têm, ou acreditam ter, algo a dizer na concepção de uma política científica: conselheiros de governo, economistas, jornalistas científicos e, enfim, a maioria da comunidade científica com mais de $\mathbf{3 0}$ anos.

Dei-me conta de que, para a minha geração, estes problemas não eram importantes ou, mesmo, náo existiam.

Fazia-se ciência pelo prazer, desde que se possuíssem condiçóes mínimas de criatividade para produzir alguma contribuição significativa no processo de compreensão da natureza.

É para mim, portanto, difícil apresentar uma contribuiçăo, pelo menos inteligente, dentro do quadro delineado; decidi então apresentar 
algumas observaçóes próprias com a única desculpa de que estas são o fruto de minha própria experiência durante inúmeros anos de vivência na USP.

\section{Histórico}

A criação do Instituto Oswaldo Cruz, no Rio, em 1900, representa a institucionalizaçáo da pesquisa no Brasil.

A criação da USP e da FFCL em 1935 constitui um marco no treinamento profissional do pesquisador brasileiro. Nessa ocasiăo, com a vinda de professores estrangeiros, formou-se a primeira massa crítica com consciência científica e os profissionais foram despertados para os problemas que inibiam o progresso científico.

O reconhecimento da necessidade de apoio e da importância da pesquisa científica para o desenvolvimento do País é, entretanto, bem mais recente. Com relaçáo a este aspecto do problema podemos dividi-lo em 3 fases:

- 1a fase: que se estendeu até a década de $\mathbf{4 0 .}$

Rockefeller - doações particulares (Mesquita).

Fundos Universitários de Pesquisa - legislativo do Estado com grande visão - Constituiçáo do Estado de 1947; artigo 123, onde se estabelece $0,5 \%$ de sua arrecadaçáo tributária para uma fundaçăo a ser criada, e com o objetivo de atender às necessidades da pesquisa no Estado.

- 2a fase: inicia-se em 51 com a criação do CNPq (sugestão da Academia Brasileira de Ciências, 1939). Objetivos: A criação e a ação positiva do CNPq fizeram viver o movimento em São Paulo para o estabelecimento de uma Fundaçăo, a fim de cumprir o artigo da Constituição estadual de 47. Assim, em 1960, a FAPESP foi criada pela lei orgânica no 5.918 durante o governo Carvalho Pinto. Esta fundaçáo tem características inéditas que discutiremos mais adiante.

Ainda na área federal, foram criados:

FNDCT FINEP

CAPES Ministério Educativo - importância do papel da Universidade

FUNTEC BNDES - pós-graduaçáo

- 3ㄹ fase: iniciada na década de 70 . Esta é caracterizada pelo reconhecimento explícito, ao nível de governo, que ciência e tecnologia são assuntos de Estado. Pela primeira vez, ciência e tecnologia figuravam ex- 
pressamente no Primeiro Plano para o Desenvolvimento para o período 72-74, reconhecidamente como elementos fundamentais para a execução de uma estratégia de desenvolvimento. Imediatamente depois, durante o período 73-74, é aprovado o Primeiro Plano Básico para o Desenvolvimento da ciência e tecnologia.

Convém aqui observar que desta forma o Brasil, a exemplo dos países avançados, reconhece que o desenvolvimento da ciência moderna está numa dependência crescente do Estado. Reconhece, também, que a crescente aplicação dos novos conhecimentos adquiridos através da pesquisa científica justifica largamente os investimentos em ciência, mas, aparentemente, náo reconhece que o desenvolvimento científico está exigindo recursos cada vez mais importantes para a continuidade de seu avanço.

Convém salientar que, de forma global, foi após a Segunda Guerra Mundial, primeiro por razóes estratégicas e depois, em nome do crescimento econômico e da competiçáo de mercado, que a ciência se tornou, de forma irreversível, um assunto de Estado. Este passou a preocupar-se com a integraçáo da pesquisa científica, objetivando, primordialmente, o desenvolvimento tecnológico.

O imenso esforço de pesquisa acionado durante a Segunda Guerra Mundial - em particular o projeto Manhattan, dedicado à produçáo em particular do primeiro artefato nuclear, e também o radar, sistemas teleguiados, computadores, penicilina - tornou a ciência "uma propriedade nacional", que pode determinar a relação de poder entre as naçóes e pode contribuir na perseguiçáo de seus objetivos, especialmente nos campos militar e econômico. Torna-se, portanto, importante explorar os resultados da pesquisa científica como mais um meio de açáo política: a ciência é então tratada como uma ferramenta ou, mesmo, como mais uma commodity.

A relação da ciência com o Estado é extremamente complicada porque, se de um lado ela depende do Estado, por outro lado ela quer, e deve manter, a sua independência - é essencial para o seu desenvolvimento como produto da criatividade.

Este é um problema antigo, já exposto claramente por Galileu na sua carta à arquiduquesa da Toscana.

No documento de criaçáo da Royal Society, consta explicitamente que a prática da ciência não deve envolver meddling with politics. Diante deste complicado relacionamento entre Estado e Ciência, convém aqui esclarecer e distinguir alguns conceitos: ciência básica e ciência aplicada; 
política científica e política para o desenvolvimento científico.

O que se entende por pesquisa básica e onde se encontra a fronteira entre a pesquisa básica e a aplicada? Freqüentemente afirma-se que não existe uma nítida separação entre a pesquisa básica e a aplicada, uma vez que, nos dois domínios, estão envolvidas pessoas com formaçāo semelhante utilizando equipamentos semelhantes em ambientes semelhantes e para executar trabalhos muito semelhantes. Permito-me não concordar: existe uma grande diferença; ela reside na escolha dos problemas.

Em pesquisa básica ou fundamental, o objetivo é a compreensáo das leis da natureza: conseqüentemente, o fenômeno a ser estudado deve ser tão simples e tão geral quanto possível. Assim, em física dos sólidos, por exemplo (onde a distinçáo com as pesquisas aplicadas é menos marcante), escolhe-se uma amostra de grande pureza química - às vezes isotópica -, com uma estrutura simples e bem conhecida, e com uma forma geométrica simples se os efeitos de superfície são importantes. Assim, o pesquisador elimina todas as complicaçōes secundárias, concentrando-se naquelas que possam permitir uma total compreensão do fenômeno.

De outro lado, na pesquisa aplicada, o objetivo é o de produzir um dispositivo útil: a compreensão total do que acontece não é necessária. A escolha da substância é ditada por consideraçôes técnicas e econômicas freqüentemente incompativeis com a simplicidade mencionada. Exemplo da tecnologia nuclear.

Os outros conceitos que pretendo esclarecer, pelo menos como eu os entendo, são os de política científica e de política para o desenvolvimento da ciência.

A política científica relaciona-se com a política de governo na utilização do conhecimento científico para o desenvolvimento. Não existe diferença entre o Brasil e os EUA no que se refere àquilo que o físico interessado na estrutura nuclear, ou o geneticista, que estuda a evolução de uma planta, desejam saber. Entretanto, quando se trata de saber que tipos de pesquisas físicas ou genéticas podem tornar-se economicamente úteis em cada um dos países, a experiência do outro país pode ser relativamente pouco importante. Cabe à política científica fazer a escolha adequada das áreas de pesquisa orientadas que permitam atingir os objetivos econômicos e sociais desejados.

A pesquisa para o desenvolvimento científico, entretanto, deve objetivar o apoio à geração do conhecimento científico, à criação científica e à preparação de recursos humanos adequados para essa finalidade. 
Preocupa-se então com a pesquisa básica e garante a sua autonomia, que é fundamental para a educaçáo científica e o avanço do conhecimento. A pesquisa básica é um tipo de seguro para o futuro; é uma das fontes para as inovaçóes tecnológicas do amanhã e da compreensão mais profunda do universo em que vivemos.

Para exemplificar, entre as áreas de pesquisa fundamental, hoje,

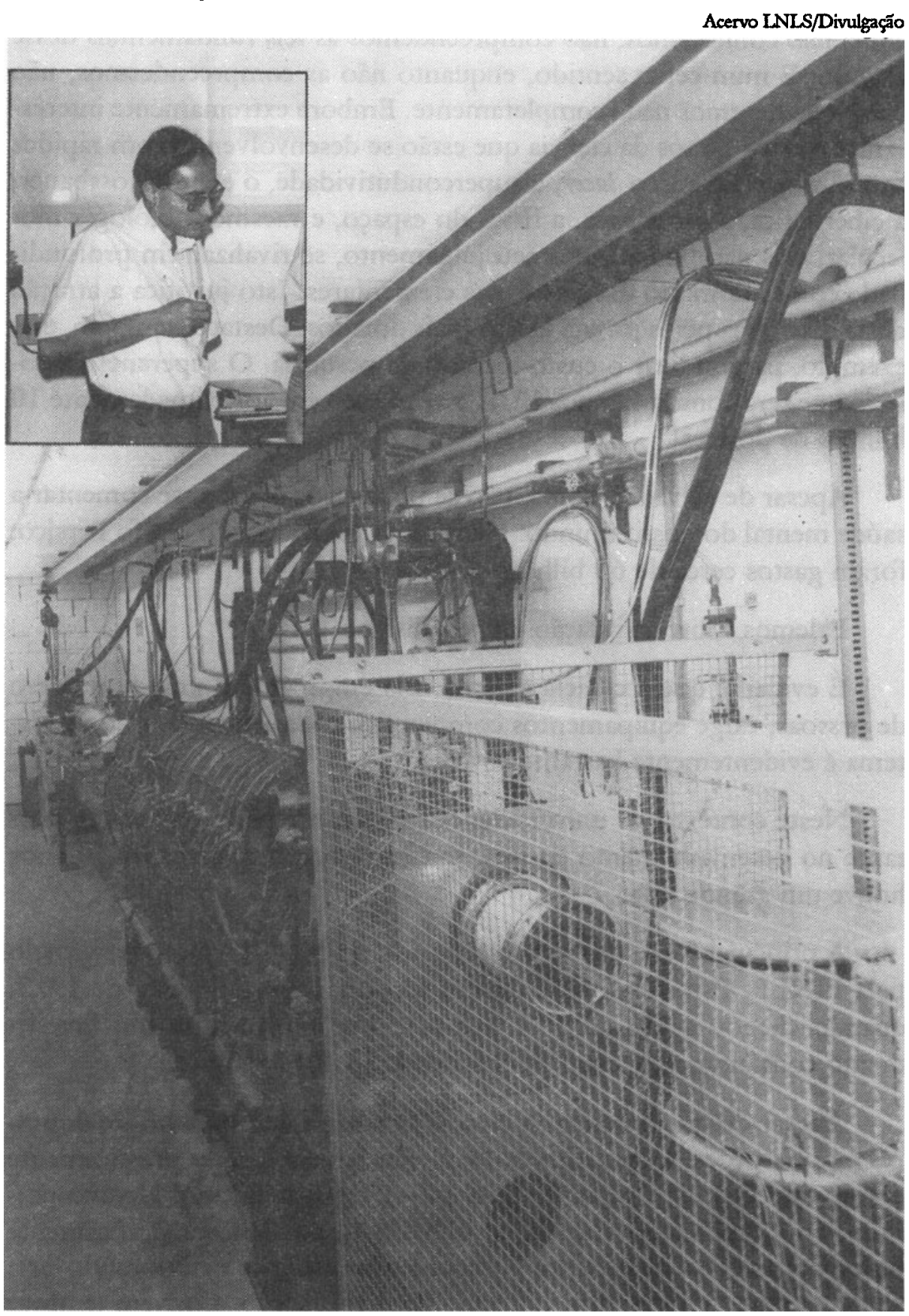


ocupa uma posiçăo destacada a física das altas energias ou física das partículas elementares. A sua importância decorre do fato de que ela se ocupa com o cerne do mundo físico, $e$ as leis que ela procura compreender e formular constituem a base de todo o universo. Apesar dos progressos importantes neste domínio, apesar da descoberta de certas regularidades nas interaçóes entre as partículas elementares - regularidades que são descritas em termos matemáticos extremamente atraentes ainda não conhecemos, năo compreendemos as leis fundamentais desse mundo. E num certo sentido, enquanto não as compreendermos, não compreenderemos nada completamente. Embora extremamente interessantes, certos ramos da ciência que estáo se desenvolvendo com rapidez extraordinária como o laser, a supercondutividade, o efeito Mössbauer, a cibernética, a astrofísica, a física do espaço, e mesmo a biologia molecular, elas não podem, no meu julgamento, se rivalizar em profundidade com o domínio das partículas elementares. Isto justifica a atraçáo desta disciplina pelos jovens físicos mais dotados. Destaco, também, este exemplo, para indicar o custo elevado da pesquisa. O superanel de colisáo que será construído nos EUA está orçado em aproximadamente 10 bilhōes de dólares!

Apesar de elevada a soma, náo se pode criticá-la sem se comentar a saúde mental do nosso mundo. Na recente guerra com o Golfo Pérsico, foram gastos cerca de 60 bilhôes de dólares!

Falemos sobre a situaçáo da pesquisa no País.

É evidente que a ciência cresceu. Ela emprega um grande número de pessoas, exige equipamentos complexos e toda a manutenção do sistema é evidentemente bastante custosa.

Neste contexto, as universidades tiveram um papel deveras importante no desenvolvimento da pesquisa entre nós. Em cerca de 50 anos houve um grande salto.

A principal fonte de recurso tem sido o FNDCT, que é gerenciado pela FINEP. Este fundo atingiu um pico máximo por volta de 1975, quando chegou a $1 \%$ do PIB nacional, que representou um investimento com um gasto anual de cerca de US\$ 40 per capita.

Apesar do crescimento da ciência brasileira, em número de doutores e publicações, o investimento em ciência vem caindo drasticamente e hoje corresponde a cerca de US\$ 10-15 per capita/ano. No ano passado, em alguns laboratórios, o dinheiro disponível era praticamente nulo. Como conseqüência, os equipamentos estáo-se deteriorando pela absoluta falta de uma infra-estrutura de manutenção. Convém lembrar 


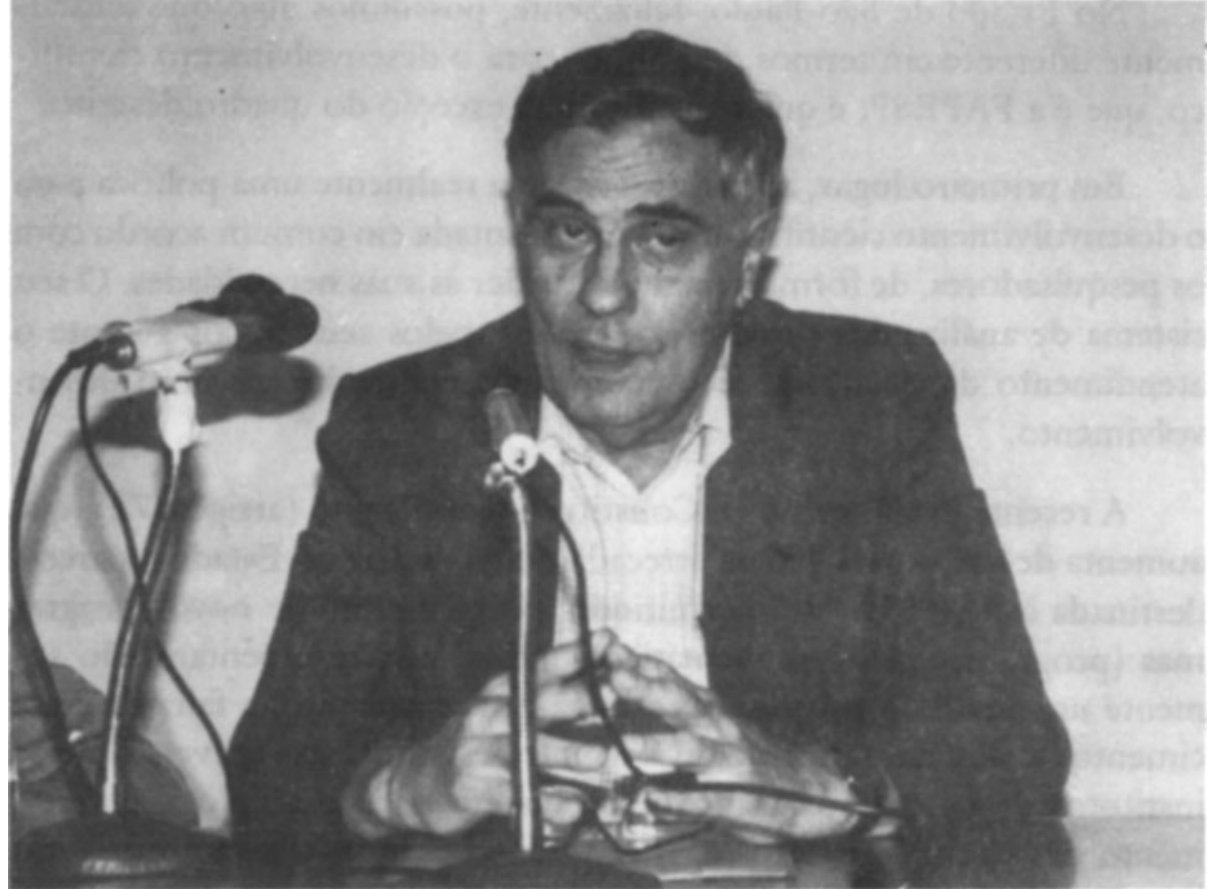

Sala: "As promessas stio muitas, mas a realidade parece ser diferente e dura"

que, como regra geral, para um dado investimento em equipamento de laboratório exige-se cerca de $20 \%-25 \%$ por ano para a sua manutenção. Nunca, em época alguma e em lugar algum no Brasil, conseguiu-se uma situação sequer semelhante. Como conseqüência, além da deterioração dos equipamentos, não existem em número e qualidade técnicos especializados, as bibliotecas não se mantêm atualizadas e a eficiência e qualidade da produção científica caem drasticamente.

Tenho conhecimento de grupos competentes e experimentados que estáo revendo os seus programas de pesquisa, abandonando problemas interessantes em que poderiam fazer significativas contribuiçōes, substituindo-os por programas triviais, a fim de não paralisarem completamente as suas atividades. A chama da criatividade pode ser extinta se não oferecermos aos pesquisadores condiçōes de exercê-la.

Tenho acompanhado, como membro do GEA, o programa PADCT. Em algumas universidades é o único programa que permite o desenvolvimento de alguma pesquisa segundo o depoimento de pesquisadores. É lamentável ver que em lugar de ser um programa suplementar aos demais fundos, ele está num crescendo. Atualmente existe uma perspectiva de corte orçamentário deste programa.

As promessas são muitas, mas a realidade parece ser diferente e dura. 
No Estado de São Paulo, felizmente, possuímos algo que é totalmente diferente em termos de política para o desenvolvimento científico, que é a FAPESP, e que constitui uma exceção do quadro descrito.

Em primeiro lugar, a FAPESP executa realmente uma política para o desenvolvimento científico e esta é implantada em comum acordo com os pesquisadores, de forma a melhor atender às suas necessidades. $O$ seu sistema de análise dos projetos, ou bolsas, pelos seus traços garante $o$ atendimento da qualidade, e o acompanhamento do seu bom desenvolvimento.

A recente modificação na Constituição do Estado (artigo 271), que aumenta de $0,5 \%$ para $1 \%$ da arrecadação tributária do Estado a parcela destinada à FAPESP, está permitindo a implantaçăo de novos programas (programas especiais, temáticos, livros) que representam não somente um auxílio à pesquisa. Preocupa-nos, entretanto, a falta de crescimento ou desenvolvimento de uma infra-estrutura nas universidades e institutos de pesquisa, que pode colocar em risco o amplo aproveitamento desses investimentos e impedindo conseqüentemente que estes investimentos possibilitem a modernizaçăo das universidades tanto ao nível de graduação como de pós-graduação.

O exemplo da FAPESP tem sido aproveitado em vários outros estados (Rio, Minas, Pernambuco, Rio Grande do Sul) e estas fundaçóes poderão desempenhar um papel de importância num processo de descentralização do apoio à pesquisa, desde que seus recursos sejam entendidos como recursos complementares ao do governo central e não substitutivos.

Compreendemos que o momento é difícil para o País, porém se não tratarmos com a devida atenção a educação e a pesquisa, se a pesquisa científica não passar a fazer parte de nossa cultura, se não tivermos condiçóes para gerar conhecimento científico e, sobretudo, se não aprendermos a utilizá-lo, então o desejo de modernização e de competitividade para a Naçăo ficará simplesmente no discurso, na retórica.

Conferência do Mês do IEA-USP feita pelo autor no dia 4 de março de 1991.

Oscar Sala é professor do Departamento de Física Nuclear do Instituto de Física da USP e presidente da Academia Brasileira de Ciência. 